\title{
Modafinil Improves Cognition and Attentional Set Shifting in Patients with Chronic Schizophrenia
}

\author{
Danielle C Turner*,', Luke Clark ${ }^{2}$, Edith Pomarol-Clotet', Peter McKenna', Trevor W Robbins ${ }^{2}$ \\ and Barbara J Sahakian*,I \\ 'Department of Psychiatry, University of Cambridge, School of Clinical Medicine, Addenbrooke's Hospital, Hills Road, Cambridge, UK; \\ ${ }^{2}$ Department of Experimental Psychology, University of Cambridge, Downing Street, Cambridge, UK
}

\begin{abstract}
Modafinil, a novel cognitive enhancer, selectively improves neuropsychological task performance in healthy volunteers and adult patients with attention deficit hyperactivity disorder (ADHD). It has been argued that persistent cognitive deficits in patients with schizophrenia are responsible for the failure of many patients to rehabilitate socially even when psychotic symptoms are in remission. The present study examined the potential of modafinil as a cognitive enhancer in schizophrenia. Twenty chronic patients with a diagnosis of schizophrenia were entered into a double-blind, randomized, placebo-controlled crossover study using a $200 \mathrm{mg}$ dose of modafinil. Modafinil had some cognitive enhancing properties in schizophrenia similar to those observed in healthy adults and adult patients with ADHD. Improvement was seen on short-term verbal memory span, with trends towards improved visual memory and spatial planning. This was accompanied by slowed response latency on the spatial planning task. No effect on stop-signal performance was seen. Importantly, significant improvement in attentional set shifting was seen, despite no effect of modafinil on this task being seen in healthy volunteers or ADHD patients. Modafinil may have potential as an important therapy for cognitive impairment in patients with schizophrenia, particularly because of its beneficial effects on attentional set shifting.

Neuropsychopharmacology (2004) 29, I363-1373, advance online publication, 7 April 2004; doi: I 0. I038/sj.npp. I 300457
\end{abstract}

Keywords: impulsivity; norepinephrine; dopamine; working memory; executive function; psychosis

\section{INTRODUCTION}

It is well established that the symptoms of schizophrenia include a range of cognitive deficits that often persist, despite significant improvements in psychotic symptoms following treatment (Goldberg et al, 1993; Mitchell et al, 2001). Pharmacological treatment of cognitive impairment has become an important intervention target in schizophrenia (Hyman and Fenton, 2003). Cognitive impairment is known to be an important determinant of functional outcome in patients with schizophrenia (Green et al, 2000; Harvey et al, 2003), with the degree of impairment often determining the level of self-care, utilization of hospital services and burden placed on relatives and caregivers by these patients (Addington et al, 2001; Davidson and Keefe, 1995; Sevy and Davidson, 1995).

\footnotetext{
*Correspondence: BJ Sahakian, Department of Psychiatry, University of Cambridge, School of Clinical Medicine, Box 189. Addenbrooke's Hospital, Hills Road, Cambridge CB2 2QQ, UK, Tel: +44-122333|209, Fax: + 44-1223-336968, E-mail: dct23@cam.ac.uk

Received 04 December 2003; revised 24 February 2004; accepted 09 March 2004

Online publication: 10 March 2004 at http://www.acnp.org/citations/ Npp03 $100403555 /$ default.pdf
}

Neuropsychological studies of patients with schizophrenia have consistently identified deficits on tests of executive function, known to be sensitive to frontal lobe damage (Goldberg et al, 1987; Goldberg et al, 2003; Kolb and Whishaw, 1983; McKenna et al, 1990; Stuss et al, 1983; Taylor and Abrams, 1987; Weinberger et al, 1986). Deficits in cognitive flexibility, working memory, and planning have been widely reported, together with more recent evidence of impairments in inhibitory control (Badcock et al, 2002; Elliott et al, 1995; Pantelis and Brewer, 1995; Pantelis et al, 1999). Moreover, cognitive flexibility, as measured by the Wisconsin Card Sorting Test (WCST), has been related to community outcome in these patients (Green, 1996; Hartman et al, 2003) and to response to psychological intervention (Wykes et al, 2003). It has been claimed that the newer generation of atypical antipsychotic drugs may have beneficial effects on cognitive function (Cassens et al, 1990; Keefe et al, 1999; Spohn and Strauss, 1989), although many of the cognitive impairments do not normalize even with these drugs (Goldberg et al, 1993).

Stimulant treatment has been used previously in the treatment of schizophrenia, most commonly in an attempt to treat patients with prominent negative symptoms (Angrist et al, 1982). However, most of these studies have reported a re-emergence or worsening of positive symptoms 
as a result of the dopaminergic activity of these drugs (Sharma et al, 1991; Szeszko et al, 1999). Nevertheless, circumstantial evidence has accumulated to suggest that stimulant treatment might be of benefit to cognitive and negative symptoms in patients with schizophrenia (Davidson and Keefe, 1995). Chiarello and Cole (1987) reported some improvement in approximately half of patients with schizophrenia who received psychostimulants, while Goldberg et al (1991) showed that amphetamine yielded a significant improvement in performance on the WCST in a group of patients sustained on haloperidol. Following methylphenidate, Carpenter et al (1992) showed possible improvements in self-reported symptoms and ward staff opinion in three out of eight patients with schizophrenia and a childhood history of hyperactivity (although no changes were noted using various other rating scales). However, in two other studies, methylphenidate significantly increased thought disorder in patients with schizophrenia (Levy et al, 1993) and increased redundant responding on an oral word production test (Szeszko et al, 1999).

We have shown that modafinil, a wake-promoting agent, has significant cognitive enhancing effects in healthy adults and adult patients with ADHD (Turner et al, 2003a; Turner et al, 2004). These effects show some similarities to the changes in cognition seen with the catecholaminergic agent methylphenidate in healthy adults (Elliott et al, 1997) and adults with ADHD (Aron et al, 2003a), despite modafinil's distinct mechanism of action (Ferraro et al, 1997; Lin et al, 1992; Lin et al, 1996; Taylor and Russo, 2000 but see Wisor et al, 2001). In both ADHD and healthy adults, modafinil significantly improved spatial planning, visual pattern recognition memory, digit span, and response inhibition. Improved accuracy was accompanied by a slowing in response latency on several tasks relative to placebo (Turner et al, 2003a; Turner et al, 2004). We concluded that modafinil may exert its effects through reducing cognitive impulsivity (Bechara et al, 2002; Evenden, 1999).

A well-defined biochemical mechanism of action of modafinil has not yet been elucidated. Nevertheless, recent evidence suggests that modafinil might be acting via a mechanism similar to the newly discovered neuropeptides orexin-A and -B (Chemelli et al, 1999; Scammell et al, 2000) to promote histamine release (Ishizuka et al, 2003). Unlike amphetamine and methylphenidate, the psychomotor effects of modafinil do not appear to be mediated via a catecholamine mechanism (Ferraro et al, 1997), which might account for modafinil's reduced side-effect profile and low abuse potential (Deroche-Gamonet et al, 2002).

Given that traditional (dopaminergic) stimulants appear to have some beneficial effects in schizophrenia (Davidson and Keefe, 1995) but with the unavoidable exacerbation of positive symptoms (Levy et al, 1993), modafinil, with its reduced dopaminergic activity, might be more appropriate for use in schizophrenia. Two case studies examining the use of modafinil in schizophrenia showed improvement in the negative symptoms of both patients and a decrease in the sedating side effects of their antipsychotic medications (Yu et al, 2002). One patient showed an increase in activity and a reversal of weight gain with modafinil. Modafinil has also been shown to improve antipsychotic-associated sedation in three patients with schizophrenia (Makela et al,
2003). We therefore sought to examine whether the beneficial cognitive effects of modafinil, seen in healthy controls and patients with ADHD, extended to patients with schizophrenia using a placebo-controlled crossover design.

\section{MATERIALS AND METHODS}

\section{Patients and Procedures}

Twenty adult chronic patients (16 male, four female) meeting the criteria for a DSM-IV diagnosis of schizophrenia (American Psychiatric Association, 1994) were recruited from the Cambridge Psychiatric Rehabilitation Service. Patients had a mean age of $43 \pm 9$ years (range 2659 years), an average NART verbal IQ (as indexed by the National Adult Reading Test, Nelson, 1982) of $110 \pm 6$ (range 100-126) and had been in formal education for an average of $13 \pm 2$ years (range 10-16 years) (Table 1). The study was approved by the Cambridge Local Research Ethics Committee and written informed consent was given by all patients prior to testing.

All patients were in a stable clinical condition, either living independently or in sheltered accommodation with support and on stabilized doses of neuroleptic medication. Eighteen patients were stabilized on clozapine (range 100$600 \mathrm{mg} /$ day), one on olanzapine ( $10 \mathrm{mg} /$ day) and one patient received a twice-monthly depot injection of pipotiazine $(75 \mathrm{mg})$. In addition, all had a Folstein Mini Mental State Examination (MMSE) (Folstein et al, 1975) score of 26 or greater to exclude marked overall intellectual impairment. The mean Global Assessment Scale score (which ranges from 0 to 100) (Endicott et al, 1976) for the group was $40.7 \pm 7.12$ (range 31-62), indicative of patients with 'major impairment in several areas, such as work, family relations, judgment, thinking, or mood'. Patients were also assessed using the Comprehensive Assessment of Symptoms and History Scale (Andreasen et al, 1992). The scales range from zero for 'no evidence of symptoms' to five for 'severe' presentation. The group mean for global severity of delusions was $1.9 \pm 1.5$, global hallucinations was $2.3 \pm 1.6$, global thought disorder was $0.9 \pm 1.2$ and global catatonia was $0.1 \pm 0.5$. The summary score for the assessment of negative symptoms was $2.4 \pm 0.9$. The mean duration of illness, from first admission to a psychiatric facility, was $17.3 \pm 9.7$ years (range $4-39$ years). The exclusion criteria included any significant motor or visual

Table I Mean age, NART IQ and Education Level for the Two Groups

\begin{tabular}{lccccc}
\hline & $\begin{array}{c}\text { P/D group, } \\
\mathbf{n = 1 0}\end{array}$ & $\begin{array}{c}\text { D/P group, } \\
\mathbf{n}=\mathbf{1 0}\end{array}$ & SE & F-value & $\boldsymbol{P}$-value \\
\hline Age (years) & $44 \pm 10$ & $42 \pm 8$ & 2.01 & 0.32 & $0.58 \mid$ \\
NART & $109 \pm 7$ & $1 \mid 1 \pm 5$ & 1.31 & 0.11 & 0.749 \\
Education & $13 \pm 2$ & $14 \pm 3$ & 0.50 & 0.80 & 0.382 \\
(years) & & & & & \\
\hline
\end{tabular}

Values shown are the mean and SDs of the mean for each group. Age is given in years, NART is the predicted verbal IQ score, education level is in years in formal education. The P/D group received placebo in session one followed by drug in session two. The D/P group received drug followed by placebo. 
impairment, the concurrent use of any medication contraindicated with modafinil, or a NART verbal IQ score of $<90$.

A randomized double-blind, placebo-controlled, crossover design was used, with 10 participants randomized to receive a single oral dose of a lactose placebo on the first session, followed by $200 \mathrm{mg}$ modafinil in the second session (the $\mathrm{P} / \mathrm{D}$ group) and 10 participants randomized to receive drug first, followed by placebo (the D/P group). Both groups were matched for age, NART verbal IQ and education level $(\mathrm{F}(1,18) \leqslant 0.80, P \geqslant 0.382)$ (Table 1$)$. For each patient, testing sessions were separated by at least a week.

This study design was chosen to maximize the detection of any cognitive effect of modafinil. Only patients in whom the positive and negative symptoms had been stable for extended periods of time, and who were expected to remain stable for the duration of the study, were included. In addition, as psychosis can affect cognitive performance and it was expected that modafinil would only be used clinically as an adjunctive treatment, all patients remained on their neuroleptic treatment for the duration of the study. A dose of $200 \mathrm{mg}$ was chosen in agreement with previous studies (Caldwell et al, 2000; Turner et al, 2003a; Turner et al, 2004). Doses higher than the recommended maximum dose of $400 \mathrm{mg} /$ day (Joint Formulary Committee, 2003) should be used with caution in schizophrenia, following a case report of a patient with schizophrenia who became agitated with extreme disorganization of speech, paranoid delusions and auditory hallucinations following $800 \mathrm{mg}$ per day of modafinil (Narendran et al, 2002).

Peak plasma concentrations of modafinil are obtained 2$3 \mathrm{~h}$ after oral administration with an elimination half-life of 10-12 h (Wong et al, 1998). Patients were, therefore, tested $2 \mathrm{~h}$ post drug administration, for approximately $2 \mathrm{~h}$.

\section{Physiological Measures}

Blood pressure and pulse measurements were taken using a Criticare Systems Inc. Comfort Cuff ${ }^{\mathrm{TM}}$ (Model 507NJ) at four time points: before drug administration, immediately prior to testing ( $2 \mathrm{~h}$ post drug), $1 \mathrm{~h}$ into testing ( $3 \mathrm{~h}$ post drug), and on completion of the study ( $4 \mathrm{~h}$ post drug).

\section{Subjective Measures}

Patients were asked to complete visual analogue scales (Bond and Lader, 1974) before the administration of the drug and at intervals during the testing session: immediately prior to testing, $1 \mathrm{~h}$ into testing, and on completion of testing. At each of the four time points, patients were asked to rate their feelings in terms of 16 dimensions. The measures used in this study were alert-drowsy, calmexcited, strong-feeble, muzzy-clear headed, well coordinated-clumsy, lethargic-energetic, contented-discontented, troubled-tranquil, mentally slow-quick witted, tenserelaxed, attentive-dreamy, incompetent-proficient, happysad, antagonistic-amicable, interested-bored, and withdrawn-gregarious. The dimensions were presented as $100 \mathrm{~mm}$ lines, the two extremes of the emotion (eg 'alert' and 'drowsy') written at each end, and patients marked their current state on each line.

\section{Psychological Measures}

Patients were tested on a comprehensive neuropsychological test battery including tests from the Cambridge Neuropsychological Test Automated Battery (CANTAB) (www.camcog.com). The tests used were the same as those used previously (Turner et al, 2003a; Turner et al, 2004), although the battery was shortened to increase patient compliance. Where available, parallel versions of the tasks were used to limit practice effects. The order in which patients received the tasks differed for the placebo and drug conditions, and was randomized across patients. All computerized tasks were run on an Advantech personal computer (Model PPC-120T-RT), and responses registered either via the touch-sensitive screen or a button box, depending on the task. The majority of the tasks have been described elsewhere and readers are directed to the cited references, which were selected for their detailed descriptions.

Computerized tests. A brief description of the key measures for each of the tasks is presented in Table 2. The computerized tests were preceded by a 'sensorimotor' task designed to familiarize the patients with the touch-sensitive computer screen and the procedures. As this was a screening task, the response measures are not reported here. CANTAB tests of visual memory administered were the pattern recognition memory (PRM) task and the delayed matching to sample (DMTS) task. The PRM task was amended, as in the previous study (Turner et al, 2004), so that a delayed recognition task was administered $20 \mathrm{~min}$ later for added sensitivity. In this version, patients were given the same two choices of abstract patterns 20 min after the original presentation (in addition to immediately after presentation) and again asked to select the pattern they remembered. Tasks taken from the CANTAB Working Memory and Planning battery were the spatial working memory (SWM) task and the spatial span (SSP) task. The test battery also included two novel variants of original CANTAB tasks to allow for greater sensitivity: a threedimensional version of the attentional set-shifting task (IDED) and the 'One-touch' Tower of London spatial planning task (NTOL). Additional tests included digit span (from the Wechsler Adult Intelligence Scale) and the stopsignal (STOP) task.

\section{Statistical Analysis}

To investigate the effect of experimental treatment upon test performance, repeated-measures analysis of variance (ANOVA) with drug (drug or placebo) as the within-subjects factor and order (P/D or $\mathrm{D} / \mathrm{P})$ as the between-subjects factor, with an additional within-subjects factor of level or difficulty if appropriate, was used. Where appropriate, the Wilcoxon's signed-rank test was used for nonparametric data.

Crossover designs have the potential problem that practice may confound the interpretation of drug effects. We attempted to reduce practice effects wherever possible by using parallel versions of the tasks. However, in instances where significant drug $\times$ order interactions or main effects of order were identified, we felt it was of 
Table 2 Summary of Neuropsychological Tests

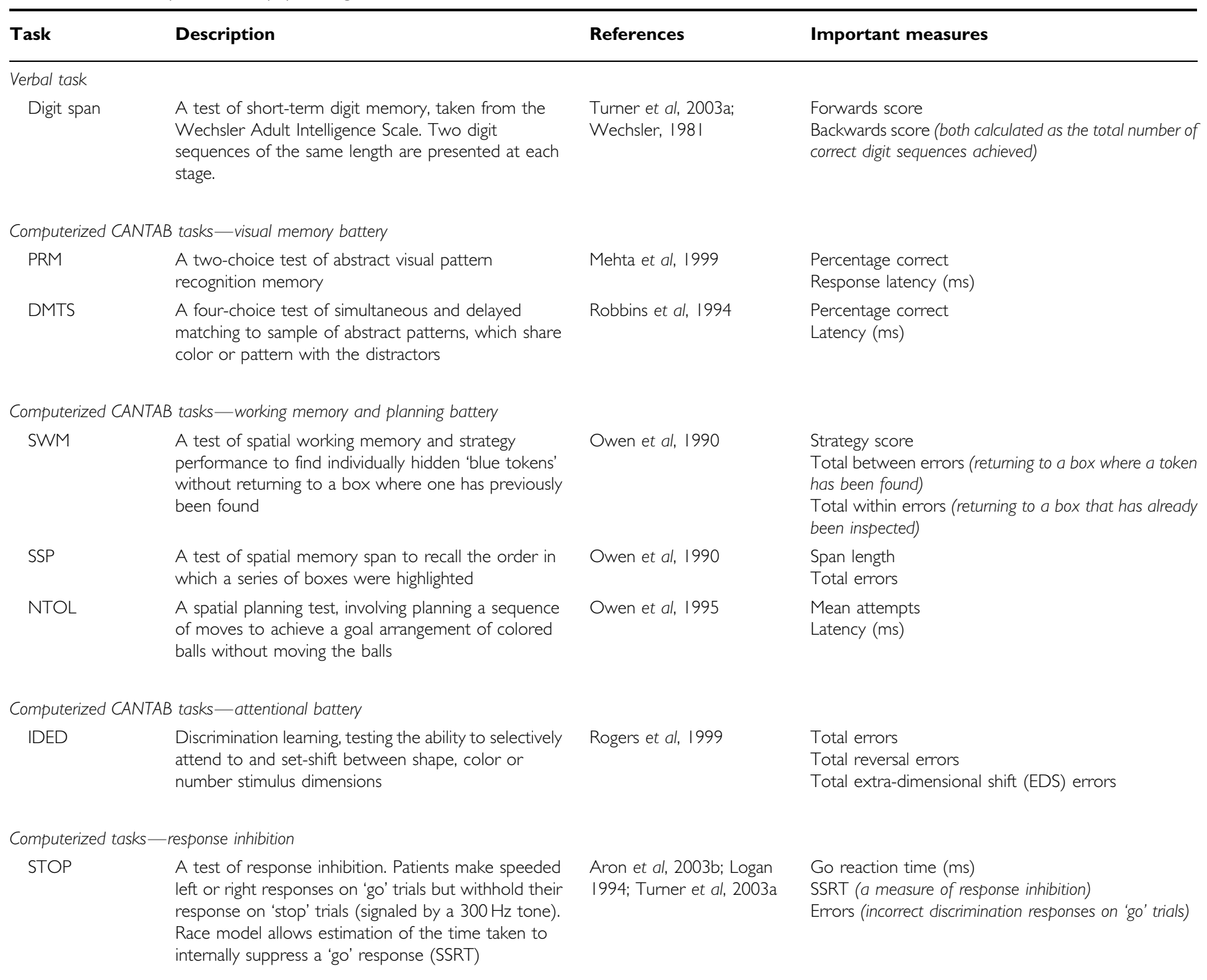

PRM = pattern recognition memory; DMTS = delayed matching to sample; SWM = spatial working memory; SSP = spatial span; NTOL= 'One-Touch' Tower of London spatial planning task; IDED = attentional set shifting; STOP = stop-signal reaction time (SSRT) task.

interest to explore the between-subjects effects on the first or second sessions alone, despite the reduced power (only 10 patients in each group). Between-group means (or the median for STOP reaction time) for single scores were analyzed using a one-way ANOVA or the equivalent Kruskal-Wallis test. Where several readings were taken for the same score, a repeated-measures ANOVA was used.

As the motivation for this study was to determine the overall cognitive profile of modafinil in schizophrenia, our interest lay equally in ascertaining the lack of an effect on particular variables, as in identifying the presence of a significant group difference on other variables. The former conclusion of a 'lack of effect' is subject to Type II errors and the latter - the presence of an effect - to Type I errors (Howell, 1997). Taking this into consideration, we have taken $P>0.1$ in reporting 'no effect' and $P<0.05$ in reporting 'an effect'.

\section{RESULTS}

\section{Physiological Effects}

Patients receiving modafinil showed no main effect of drug on systolic blood pressure, diastolic blood pressure or pulse $(\mathrm{F}(1,18) \leqslant 1.24$, NS). There was, however, a significant drug $\times$ time interaction for systolic blood pressure $(\mathrm{F}(3,54)=2.81, \quad P=0.048)$, with patients on modafinil showing a more fluctuating physiological response over the testing session compared to when receiving placebo (Figure 1). There were no other drug $\times$ time interactions $(\mathrm{F}(3,54) \leqslant 1.11$, NS).

\section{Subjective Effects}

There were no main effects of drug or drug $\times$ time effects on any of the subjective measures $(P>0.1)$. Two patients 

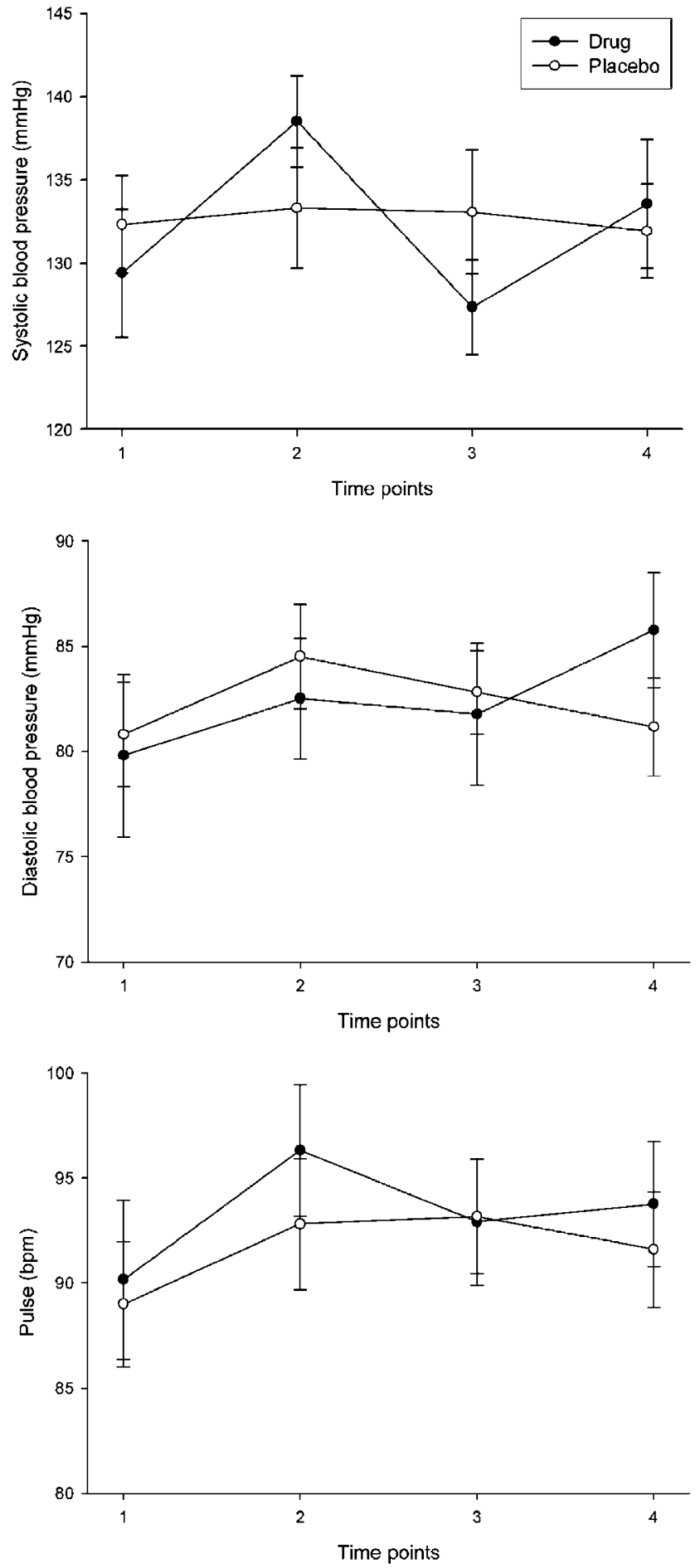

Figure I Physiological response to modafinil. Physiological effects of modafinil were apparent in terms of a significant drug $\times$ time interaction on systolic blood pressure $(P=0.048)$. There was no main effect of drug on systolic blood pressure, diastolic blood pressure or pulse $(P>0.2)$.

volunteered information with regard to how they felt on completion of both sessions, although this information was not expressly sought. One patient said the feelings he experienced following the second session were reminiscent of the first time he had taken clozapine, and the other patient said he had been unable to sleep the night following the first testing session (both sessions were later determined to have been the drug sessions). No other reports were made. In addition, no changes in symptomatology were noted in any of the patients by the two psychiatrists (EP-C and PM), with whom the patients had regular contact.

\section{Psychological Effects}

As shown in Table 3, performance on several of the tests (namely, DMTS, SWM, and SSP) did not differ between the drug and placebo conditions. In contrast, effects of modafinil were seen on tests of digit span, PRM, IDED, NTOL, and STOP. These effects are considered in more detail below. In addition, there was no main effect of order on any of the variables $(P>0.1)$ except NTOL latency (this is also discussed below).

Digit span. Modafinil resulted in a significant improvement in accuracy in both forwards score $(\mathrm{F}(1,18)=6.81$, $P=0.018)$ and backwards score $(\mathrm{F}(1,18)=9.60, P=0.006)$ (scores are calculated as the total number of digit sequences achieved; Wechsler, 1981). There were no significant drug $\times$ order interactions for either forwards or backwards score $(\mathrm{F}(1,18) \leqslant 2.40, \mathrm{NS})$.

Pattern recognition memory. Modafinil showed a trend towards improving accuracy on the delayed $(\mathrm{F}(1,18)=3.06$, $P=0.097)$ but not the immediate version of this task $(\mathrm{F}(1,18)=0.06, \mathrm{NS})$. There was no main effect of modafinil on latency on this task $(\mathrm{F}(1,18) \leqslant 2.72$, NS). There were no significant drug $\times$ order interactions with respect to accuracy or latency on either the immediate or delayed versions of this task $(\mathrm{F}(1,18) \leqslant 2.13, \mathrm{NS})$.

IDED. Patients receiving modafinil performed significantly better compared to when receiving placebo. In this task, if subjects fail to reach criterion (six consecutive correct responses) at any of the eight stages, the task is terminated. While healthy adults reliably complete this task, patients with schizophrenia typically show high attrition rates (Elliott et al, 1995; Pantelis et al, 1999). In this study, 50\% of patients failed to complete the task on placebo, but this was significantly ameliorated by modafinil ( $50 \%$ completed the task on placebo, $85 \%$ on modafinil; $\chi^{2}=5.58, \mathrm{df}=1$, $P<0.025$ ) (Figure 2). Analysis by stage revealed that significantly more patients failed at the complex extradimensional (ED) shift stage on placebo than on drug $\left(\chi^{2}=3.96, \mathrm{df}=1, P<0.05\right)$. There were no significant differences between the proportion of subjects completing any of the other stages $(P>0.1)$. Analysis of the number of errors made at each stage revealed that patients also made significantly fewer errors on modafinil at the ED stage of the task $(\mathrm{F}(1,18)=4.93, P=0.039)$, and showed a trend towards making fewer errors on drug at the IR stage $(\mathrm{Z}=1.92$, $P=0.055)$. There were no other significant differences in error rates at any of the other stages of the task, on total errors or total reversal errors $(P>0.1)$. There were no significant effects of modafinil on latency on this task $(\mathrm{F}(1,18)=0.06$, NS) and there were no significant drug $\times$ order interactions on any task variables $(P>0.1)$. 
Table 3 Summary of Test Results

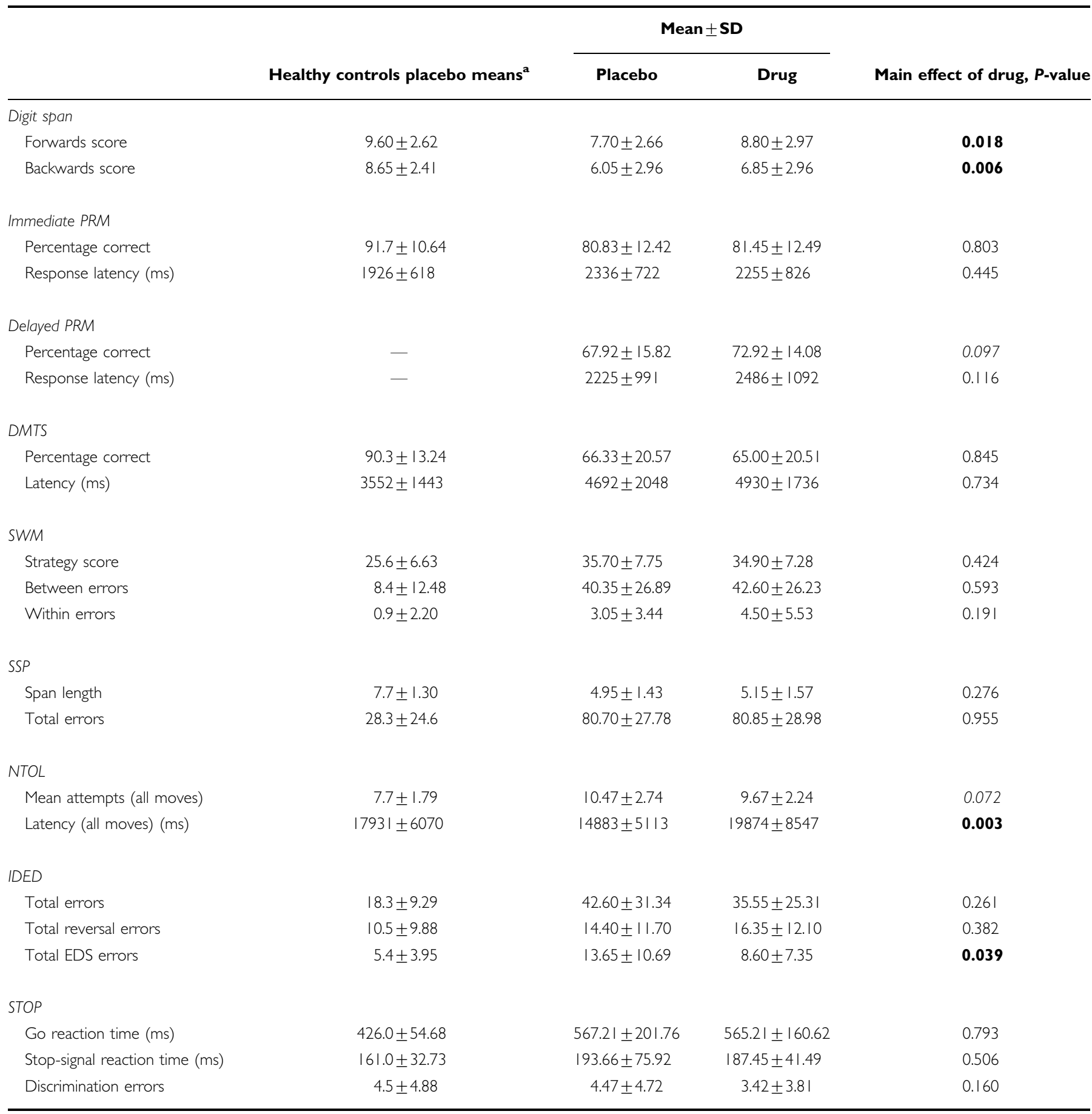

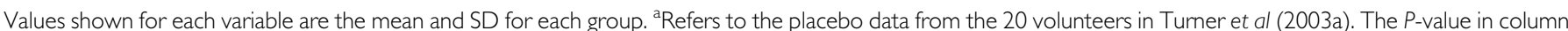
four refers to the placebo-drug effect in the schizophrenia group. Abbreviations are as for Table 2 . Bold indicates values with $P<0.05$ and italics with $0.05 \leqslant P \leqslant 0.1$.

NTOL. Two patients were unable to complete the training stage for this task as they found it too difficult. They were excluded from the analysis. For the remaining 18 patients, a trend towards patients requiring fewer attempts to obtain a correct solution on modafinil was seen $(F(1,16)=3.70$, $P=0.072$ ), although there was no significant drug $\times$ move interaction $(\mathrm{F}(5,80)=0.91$, NS) (Figure 3). This trend towards an improvement in accuracy was accompanied by a significant slowing in latency on modafinil (main effect of drug, $\mathrm{F}(1,16)=12.06, P=0.003$ ), together with a trend towards a significant drug $\times$ move interaction $(\mathrm{F}(5,80)=2.11, P=0.073)$ - patients were slowest on drug at the five-move problem. There was no significant drug $\times$ order interaction for accuracy $(F(1,16)=0.01$, NS) or latency $(F(1,16)=0.46, N S)$. There was, however, a significant main effect of order for latency $(F(1,16)=8.00$, 


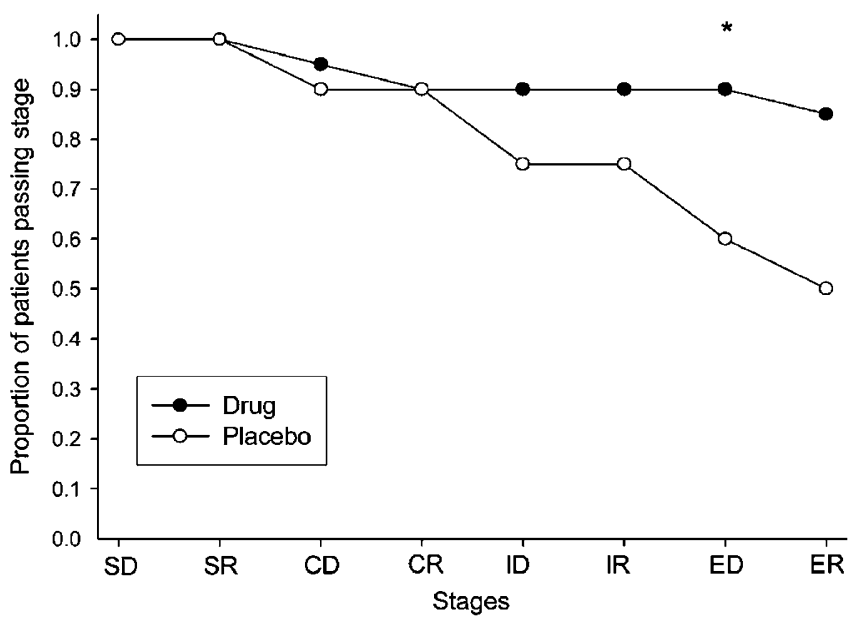

Figure 2 Effect of modafinil on attentional set shifting. Patients receiving modafinil performed significantly better at this task than when receiving placebo. Significantly more patients passed the ED stage of the task on modafinil $\left(\chi^{2}=3.96, \mathrm{df}=1, P<0.05\right)$. The stages of the task are SD (simple discrimination), SR (simple reversal), CD (compound discrimination), CR (compound reversal), ID (intra-dimensional shift), IR (intradimensional reversal), ED (extra-dimensional shift), ER (extra-dimensional reversal). $* P<0.05$
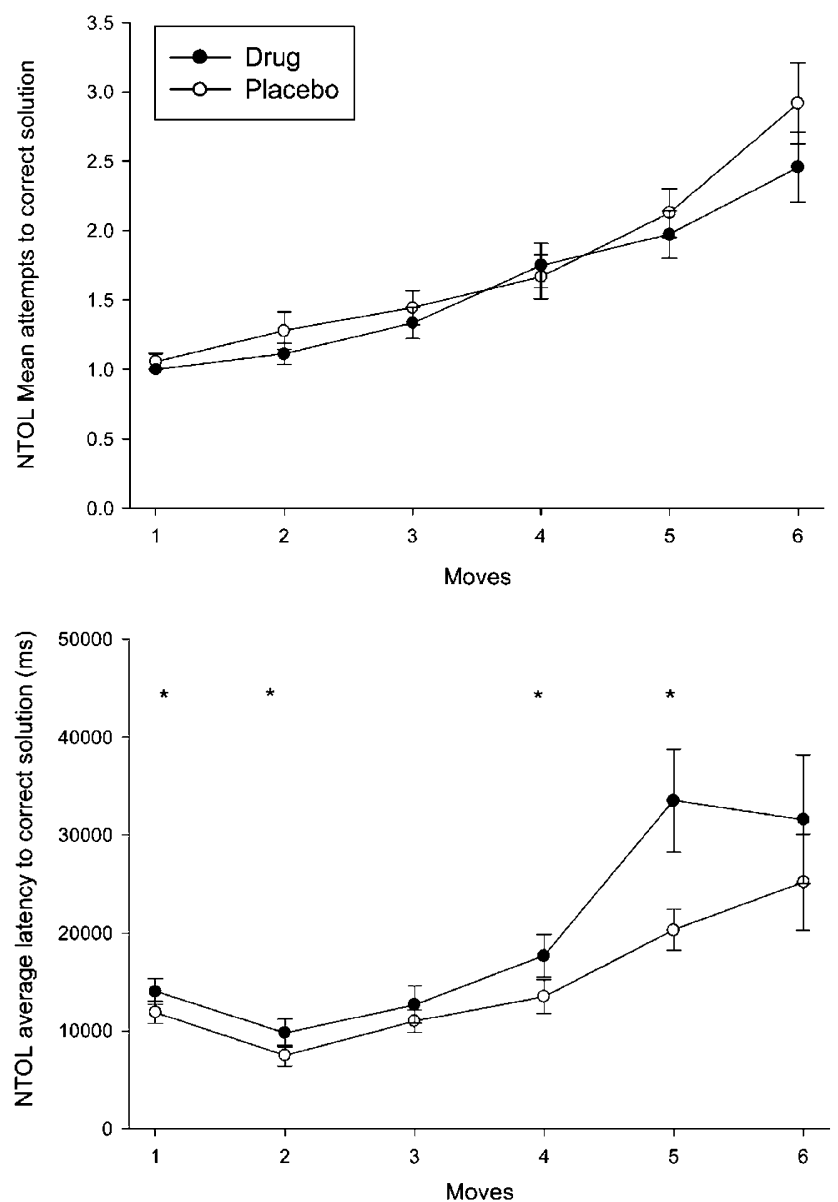

Figure 3 Effect of modafinil on the 'One-touch' Tower of London spatial planning task. Patients on drug showed a trend towards making fewer attempts to achieve the correct answer compared to those on placebo $(P=0.072)$. Patients on modafinil also took significantly longer to select their answer $(P=0.003)$. ${ }^{*} P<0.05$.
$P=0.012$ ). We therefore performed an analysis on the between-subjects data from the first and second sessions independently to identify the nature of this main effect. This showed that patients receiving modafinil were significantly slower than those receiving placebo $(\mathrm{F}(1,16)=17.25$, $P=0.001)$ at the first session, but that there was no difference between the groups at the second session $(\mathrm{F}(1,16)=0.65, \mathrm{NS})$. This confirmed the effect of modafinil on latency.

STOP. One patient did not complete this test on the first session due to time constraints. The results are, therefore, presented for the remaining 19 patients. There was no main effect of modafinil on STOP errors $(\mathrm{F}(1,17)=2.16$, NS), median reaction time $(\mathrm{F}(1,17)=0.07, \mathrm{NS})$ or stop-signal reaction time (SSRT) $(\mathrm{F}(1,17)=0.46, \mathrm{NS})$. There was, however, a significant drug $\times$ order interaction on both the median reaction time $(\mathrm{F}(1,17)=9.09, P=0.008)$ and SSRT $(\mathrm{F}(1,17)=11.77, P=0.003)$. In the case of the median reaction time, this was due to a significant speeding of latency on the second session compared to the first drug session for the $\mathrm{D} / \mathrm{P}$ group $(\mathrm{F}(1,8)=10.46, P=0.010)$, while there was no significant difference in latency across the two sessions for the P/D group $(F(1,8)=3.02$, NS). For SSRT, the interaction was due to a significant improvement in SSRT by both groups on the second session $(F(1,8) \geqslant 5.71$, $P \leqslant 0.041$ ), most likely as a result of practice effects. A between-subjects analysis of the first session on these variables showed no effect of modafinil $(\mathrm{F}(1,17) \leqslant 0.43$, NS). There was no main effect of order on any variable $(P>0.1)$.

\section{DISCUSSION}

The results of this study demonstrate that, in patients with schizophrenia, modafinil is associated with a specific pattern of cognitive enhancement. The most striking change was the effect of modafinil on attentional set shifting. Patients on modafinil passed significantly more stages of the IDED task and made significantly fewer errors at the ED stage. This task was unaffected by modafinil in both of the previous studies (Turner et al, 2003a; Turner et al, 2004), despite the ADHD group also showing IDED impairments compared with the healthy volunteer group, indicating a selective response by schizophrenic patients to modafinil on this task.

In addition, modafinil significantly improved performance on tests of digit span and showed trends towards improving visual memory (delayed PRM) and spatial planning (NTOL). These effects were accompanied by a slowing in latency with modafinil on the NTOL task. This slowing did not appear to be a simple psychomotor effect of drug, as standard reaction time (measured by the median 'go' reaction time on the STOP task) was unaffected by modafinil. Modafinil did not affect DMTS or STOP performance. Subjectively, patients did not record any significant effect of modafinil according to the visual analogue scales. However, it is possible that this was due to a lack of insight by the patients into their changing mood as two patients volunteered information, suggesting that they experienced some subjective changes to modafinil. In previous studies (Turner et al, 2003a, b; Turner et al, 2004), 
a decrease in blood pressure has been seen throughout testing sessions. In contrast, patients in this study did not show the expected reduction in blood pressure and also showed a reduced physiological response to modafinil in comparison with our previous studies (Turner et al, 2003a; Turner et al, 2004), although subtle effects on systolic blood pressure were seen.

Modafinil appears to have some consistent effects on cognition across different groups. Similar to the effects seen in schizophrenia, verbal memory span, visual memory, and spatial planning are improved in healthy volunteers and patients with ADHD (Turner et al, 2003a; Turner et al, 2004). In the same way, modafinil has consistent effects on latency, with significant slowing seen on tests such as spatial planning, but no change on simple psychomotor responding. However, in contrast to these common effects, modafinil also has some specific effects in schizophrenia. No effect was noted on STOP performance in schizophrenia, despite modafinil significantly improving the inhibition of prepotent responding in healthy adults and those with ADHD (Turner et al, 2003a; Turner et al, 2004). In the present study, modafinil also significantly improved performance on the IDED task, an effect not seen in the previous groups. These findings contrast with the effects seen with methylphenidate in healthy volunteers on tests taken from the same battery. Methylphenidate has been shown to affect measures of working memory and sustained attention (Elliott et al, 1997) that are not affected by modafinil. Methylphenidate has, however, also been shown to enhance ED shift learning in the IDED task, together with a slowing in response latency (Rogers et al, 1999). This effect is similar to that seen with modafinil in schizophrenia, suggesting that modafinil and methylphenidate have some common neurochemical bases (see Turner et al, 2004).

The effect of modafinil in schizophrenia on attentional set shifting was particularly evident at the ED stage of the task, a stage akin to the core component of the WCST (Pantelis et al, 1999), and one that has been shown previously to be impaired in schizophrenia (Elliott et al, 1995). Young, community-based patients with schizophrenia showed high levels of perseveration at the ED stage, with only half of the patients successfully completing the task in that study (Elliott et al, 1995). One explanation provided for this performance deficit is that patients with schizophrenia make perseverative errors due to a failure to inhibit responses to the previously relevant dimension (Pantelis and Brewer, 1995), although exaggerated learned irrelevance can also potentially produce the ED shift deficit (Owen et al, 1993). Given that modafinil might be acting through mechanisms associated with impulsive control to ameliorate this deficit, it would be of interest in the future to attempt to dissociate the effects of modafinil on perseveration and learned irrelevance.

Performance on the IDED task may be a useful index of cognitive deterioration in schizophrenia. In first-episode patients, impairments seen on the IDED task are relatively mild, despite pronounced deficits in planning and SWM (Hutton et al, 1998). Improvements in task performance on some cognitive tests have been observed during the first year following medication, although performance on the IDED task continues to deteriorate further (Joyce et al,
1999) to the low level of performance seen in chronic, hospitalized cases (Pantelis et al, 1999). It is unknown at present if this deterioration in IDED performance is a consequence of disease progression or neuroleptic medication. However, the patients exhibiting the greatest decline were those with the longest duration of untreated psychosis (Joyce et al, 2002), suggesting a disease-related rather than medication-related cause. Nevertheless, our finding that IDED impairment in chronic schizophrenia is ameliorated by modafinil shows that the set-shifting impairments in schizophrenia are susceptible to pharmacological intervention.

Evidence of modafinil's effect on impulsive control is supported by the observation that patients reflected longer on the NTOL test of planning when receiving modafinil, together with a trend towards an improvement in performance. This alteration in the speed-accuracy trade-off has been demonstrated in the two previous studies (Turner et al, 2003a; Turner et al, 2004) and accords with theories of reflection in which performance is impaired due to a deficit in utilizing available information before making a decision (Evenden, 1999). Patients with schizophrenia tend to plan their actions less in advance and have less sophisticated planning strategies (Jogems-Kosterman et al, 2001). It has been claimed that the tendency to accept beliefs on the basis of inadequate information processing may contribute to delusions in patients with schizophrenia (Garety et al, 2001).

Interestingly, however, no effect of modafinil was noted on SSRT, a measure of motor impulsivity. This measure was improved by modafinil in both healthy controls (Turner et al, 2003a) and patients with ADHD (Turner et al, 2004). Patients with schizophrenia showed significantly slower response execution times (go reaction time) performing a STOP task, but their estimated speed of inhibition (SSRT) is not significantly different from that of healthy controls (Badcock et al, 2002). This is in contrast with ADHD and conduct disorder, where poor response inhibition is consistently related to slower stop-signal reaction times and not to impaired reaction times (Oosterlaan et al, 1998). Differences in neural response in patients with schizophrenia when performing a STOP task have been observed (Rubia et al, 2001), and these might account for the lack of effect of modafinil on this task. Further research into the mechanism of action of modafinil is necessary to explain how modafinil is exerting its effects in schizophrenia.

In addition, further work is needed to confirm modafinil's effect on a wider range of patients with schizophrenia. A specific deficit in the attentional set-shifting task at the ED shift has been demonstrated in young, stabilized patients (Elliott et al, 1995). However, more generalized cognitive deficits on this task have been noted in more severely ill patients with schizophrenia (Pantelis et al, 1999). These patients failed to 'learn set' and were impaired at both setshifting and concept formation. This appears to be related to symptomatology, with patients who dropped out at the ED stage having higher negative symptom scores compared to those failing at the ID stage who had lower scores for bradyphrenia (slowness of thought) (Pantelis et al, 1999). These differences could reflect a larger number of compromised neural systems in the more severely ill 
patients, and thus it is important that future studies establish whether the beneficial effects of modafinil are still maintained in more severely affected patients. The effect on patients treated with a wider range of typical and atypical antipsychotics should also be examined. Treatment with clozapine is typically reserved for patients who have been unresponsive to or intolerant of conventional antipsychotics (Joint Formulary Committee, 2003), and in itself has been associated with ameliorated cognitive dysfunction (McGurk, 1999 but see Goldberg et al, 1993). In addition, it is important that these results are confirmed with long-term chronic administration studies. Although there is evidence that cognitive impairments are invariable over time (Heaton et al, 2001; Wykes et al, 2000), it is not clear that cognitive improvements would show a similar pattern of invariability.

It has been suggested that even small improvements in cognition may be clinically relevant to schizophrenia. Buchanan et al (1994) found that changes in memory over 1 year were correlated with changes in quality of life, while Wykes et al (1999) reported that a change in cognitive flexibility related to improvement in social functioning. Similarly, improvements in card sorting have been associated with improved social competence and improvements in verbal memory with increased acquisition of psychosocial skills (Spaulding et al, 1999). Davidson and Keefe (1995) proposed that in younger patients, improvements in executive functions and planning equivalent to even a change of one more category on the WCST could enable the patient to organize himself enough to live independently outside a psychiatric institution. Therefore it is hopeful that, if cognitive deficits are the determinants of functional limitations, effective treatment of cognitive deficits will lead to functional improvements. If these improvements with modafinil, as demonstrated in the present data, are confirmed with long-term administration studies, these findings will have clear relevance for clinical practice.

\section{ACKNOWLEDGEMENTS}

We thank the patients for participating in this study, which was funded by a Wellcome Trust Programme grant awarded to Professors TW Robbins, BJ Everitt, BJ Sahakian, and Dr AC Roberts, and completed within the MRC (UK) Centre for Behavioural and Clinical Neuroscience. DCT was funded by a Research Studentship from the Medical Research Council of the UK. BJS and TWR are consultants for Cambridge Cognition Ltd.

\section{REFERENCES}

Addington J, Addington D, Gasbarre L (2001). Neurocognitive and social functioning in schizophrenia and other diagnoses. Schizophr Res 48: 367-368.

American Psychiatric Association (1994). Diagnostic and Statistical Manual of Mental Disorders, 4th edn American Psychiatric Press: Washington, DC.

Andreasen NC, Flaum M, Arndt S (1992). The comprehensive assessment of symptoms and history (CASH). An instrument for assessing diagnosis and psychopathology. Arch Gen Psychiatry 49: 615-623.
Angrist B, Peselow E, Rubinstein M, Corwin J, Rotrosen J (1982). Partial improvement in negative schizophrenic symptoms after amphetamine. Psychopharmacology (Berl) 78: 128-130.

Aron AR, Dowson JH, Sahakian BJ, Robbins TW (2003a). Methylphenidate improves response inhibition in adults with attention-deficit/hyperactivity disorder. Biol Psychiatry 54: $1465-1468$.

Aron AR, Fletcher PC, Bullmore ET, Sahakian BJ, Robbins TW (2003b). Stop-signal inhibition disrupted by damage to right inferior frontal gyrus in humans. Nat Neurosci 6: 115-116.

Badcock JC, Michie PT, Johnson L, Combrinck J (2002). Acts of control in schizophrenia: dissociating the components of inhibition. Psychol Med 32: 287-297.

Bechara A, Tranel D, Damasio AR (2002). The somatic marker hypothesis and decision-making. In J. Grafman (ed). Handbook of Neuropsychology, 2nd edn, Vol. 7. Elsevier Science BV: Amsterdam. pp 117-143.

Bond A, Lader M (1974). The use of analogue scales in rating subjective feelings. Br J Med Psychol 47: 211-218.

Buchanan RW, Holstein C, Breier A (1994). The comparative efficacy and long-term effect of clozapine treatment on neuropsychological performance. Biol Psychiatry 36: 717-725.

Caldwell Jr JA, Caldwell JL, Smythe III NK, Hall KK (2000). A double-blind, placebo-controlled investigation of the efficacy of modafinil for sustaining the alertness and performance of aviators: a helicopter simulator study. Psychopharmacology (Berl) 150: 272-282.

Carpenter MD, Winsberg BG, Camus LA (1992). Methylphenidate augmentation therapy in schizophrenia. J Clin Psychopharmacol 12: $273-275$.

Cassens G, Inglis AK, Appelbaum PS, Gutheil TG (1990). Neuroleptics: effects on neuropsychological function in chronic schizophrenic patients. Schizophr Bull 16: 477-499.

Chemelli RM, Willie JT, Sinton CM, Elmquist JK, Scammell T, Lee C et al (1999). Narcolepsy in orexin knockout mice: molecular genetics of sleep regulation. Cell 98: 437-451.

Chiarello RJ, Cole JO (1987). The use of psychostimulants in general psychiatry. A reconsideration. Arch Gen Psychiatry 44: 286-295.

Davidson M, Keefe RS (1995). Cognitive impairment as a target for pharmacological treatment in schizophrenia. Schizophr Res 17: 123-129.

Deroche-Gamonet V, Darnaudery M, Bruins-Slot L, Piat F, Le Moal M, Piazza PV (2002). Study of the addictive potential of modafinil in naive and cocaine-experienced rats. Psychopharmacology (Berl) 161: 387-395.

Elliott R, McKenna PJ, Robbins TW, Sahakian BJ (1995). Neuropsychological evidence for frontostriatal dysfunction in schizophrenia. Psychol Med 25: 619-630.

Elliott R, Sahakian BJ, Matthews K, Bannerjea A, Rimmer J, Robbins TW (1997). Effects of methylphenidate on spatial working memory and planning in healthy young adults. Psychopharmacology (Berl) 131: 196-206.

Endicott J, Spitzer RL, Fleiss JL, Cohen J (1976). The global assessment scale. A procedure for measuring overall severity of psychiatric disturbance. Arch Gen Psychiatry 33: 766-771.

Evenden JL (1999). Varieties of impulsivity. Psychopharmacology (Berl) 146: 348-361.

Ferraro L, Antonelli T, O'Connor WT, Tanganelli S, Rambert FA, Fuxe K (1997). Modafinil: an antinarcoleptic drug with a different neurochemical profile to D-amphetamine and dopamine uptake blockers. Biol Psychiatry 42: 1181-1183.

Folstein MF, Folstein SE, McHugh PR (1975). 'Mini-mental state'. A practical method for grading the cognitive state of patients for the clinician. J Psychiatr Res 12: 189-198.

Garety PA, Kuipers E, Fowler D, Freeman D, Bebbington PE (2001). A cognitive model of the positive symptoms of psychosis. Psychol Med 31: 189-195. 
Goldberg TE, Bigelow LB, Weinberger DR, Daniel DG, Kleinman JE (1991). Cognitive and behavioral effects of the coadministration of dextroamphetamine and haloperidol in schizophrenia. Am J Psychiatry 148: 78-84.

Goldberg TE, Egan MF, Gscheidle T, Coppola R, Weickert T, Kolachana BS et al (2003). Executive subprocesses in working memory: relationship to catechol-O-methyltransferase Val158Met genotype and schizophrenia. Arch Gen Psychiatry 60: 889-896.

Goldberg TE, Greenberg RD, Griffin SJ, Gold JM, Kleinman JE, Pickar D et al (1993). The effect of clozapine on cognition and psychiatric symptoms in patients with schizophrenia. $\mathrm{Br} J$ Psychiatry 162: 43-48.

Goldberg TE, Weinberger DR, Berman KF, Pliskin NH, Podd MH (1987). Further evidence for dementia of the prefrontal type in schizophrenia? A controlled study of teaching the Wisconsin Card Sorting Test. Arch Gen Psychiatry 44: 1008-1014.

Green MF (1996). What are the functional consequences of neurocognitive deficits in schizophrenia? Am J Psychiatry 153: 321-330.

Green MF, Kern RS, Braff DL, Mintz J (2000). Neurocognitive deficits and functional outcome in schizophrenia: are we measuring the 'right stuff'? Schizophr Bull 26: 119-136.

Hartman M, Steketee MC, Silva S, Lanning K, Andersson C (2003). Wisconsin card sorting test performance in schizophrenia: the role of working memory. Schizophr Res 63: 201-217.

Harvey PD, Geyer MA, Robbins TW, Krystal JH (2003). Cognition in schizophrenia: from basic science to clinical treatment. Psychopharmacology (Berl) 169: 213-214.

Heaton RK, Gladsjo JA, Palmer BW, Kuck J, Marcotte TD, Jeste DV (2001). Stability and course of neuropsychological deficits in schizophrenia. Arch Gen Psychiatry 58: 24-32.

Howell DC (1997). Statistical Methods for Psychology, 4th edn. Wadsworth Publishing Company: London.

Hutton SB, Puri BK, Duncan LJ, Robbins TW, Barnes TR, Joyce EM (1998). Executive function in first-episode schizophrenia. Psychol Med 28: 463-473.

Hyman SE, Fenton WS (2003). Medicine. What are the right targets for psychopharmacology? Science 299: 350-351.

Ishizuka T, Sakamoto Y, Sakurai T, Yamatodani A (2003). Modafinil increases histamine release in the anterior hypothalamus of rats. Neurosci Lett 339: 143-146.

Jogems-Kosterman BJ, Zitman FG, Van Hoof JJ, Hulstijn W (2001). Psychomotor slowing and planning deficits in schizophrenia. Schizophr Res 48: 317-333.

Joint Formulary Committee (2003). British National Formulary, 46th edn. British Medical Association and Royal Pharmaceutical Society of Great Britain: London.

Joyce E, Hutton S, Ambery F, Robbins TW, Barnes TRF (1999). Improvement or deterioration in different executive cognitive processes early in the course of schizophrenia. Schizophr Res 36: 138.

Joyce E, Hutton S, Mutsatsa S, Gibbins H, Webb E, Paul S et al (2002). Executive dysfunction in first-episode schizophrenia and relationship to duration of untreated psychosis: the West London Study. Br J Psychiatry Suppl 43: s38-s44.

Keefe RS, Silva SG, Perkins DO, Lieberman JA (1999). The effects of atypical antipsychotic drugs on neurocognitive impairment in schizophrenia: a review and meta-analysis. Schizophr Bull 25: 201-222.

Kolb B, Whishaw IQ (1983). Performance of schizophrenic patients on tests sensitive to left or right frontal, temporal, or parietal function in neurological patients. J Nerv Ment Dis 171: 435-443.

Levy DL, Smith M, Robinson D, Jody D, Lerner G, Alvir J et al (1993). Methylphenidate increases thought disorder in recent onset schizophrenics, but not in normal controls. Biol Psychiatry 34: 507-514.
Lin JS, Hou Y, Jouvet M (1996). Potential brain neuronal targets for amphetamine-, methylphenidate-, and modafinil-induced wakefulness, evidenced by c-fos immunocytochemistry in the cat. Proc Natl Acad Sci USA 93: 14128-14133.

Lin JS, Roussel B, Akaoka H, Fort P, Debilly G, Jouvet M (1992). Role of catecholamines in the modafinil and amphetamine induced wakefulness, a comparative pharmacological study in the cat. Brain Res 591: 319-326.

Logan GD (1994). On the ability to inhibit thought and action. In: Carr TH (ed). Inhibitory Processes in Attention, Memory and Language. Academic Press: San Diego. pp 189-239.

Makela EH, Miller K, Cutlip II WD (2003). Three case reports of modafinil use in treating sedation induced by antipsychotic medications. J Clin Psychiatry 64: 485-486.

McGurk SR (1999). The effects of clozapine on cognitive functioning in schizophrenia. J Clin Psychiatry 60(Suppl 12): 24-29.

McKenna PJ, Tamlyn D, Lund CE, Mortimer AM, Hammond S, Baddeley AD (1990). Amnesic syndrome in schizophrenia. Psychol Med 20: 967-972.

Mehta MA, Sahakian BJ, McKenna PJ, Robbins TW (1999). Systemic sulpiride in young adult volunteers simulates the profile of cognitive deficits in Parkinson's disease. Psychopharmacology (Berl) 146: 162-174.

Mitchell RL, Elliott R, Woodruff PW (2001). fMRI and cognitive dysfunction in schizophrenia. Trends Cogn Sci 5: 71-81.

Narendran R, Young CM, Valenti AM, Nickolova MK, Pristach CA (2002). Is psychosis exacerbated by modafinil? Arch Gen Psychiatry 59: 292-293.

Nelson H (1982). National Adult Reading Test Manual. Windsor NFER-Nelson: UK.

Oosterlaan J, Logan GD, Sergeant JA (1998). Response inhibition in $\mathrm{AD} / \mathrm{HD}, \mathrm{CD}$, comorbid $\mathrm{AD} / \mathrm{HD}+\mathrm{CD}$, anxious, and control children: a meta-analysis of studies with the stop task. J Child Psychol Psychiatry 39: 411-425.

Owen AM, Downes JJ, Sahakian BJ, Polkey CE, Robbins TW (1990). Planning and spatial working memory following frontal lobe lesions in man. Neuropsychologia 28: 1021-1034.

Owen AM, Roberts AC, Hodges JR, Summers BA, Polkey CE, Robbins TW (1993). Contrasting mechanisms of impaired attentional set-shifting in patients with frontal lobe damage or Parkinson's disease. Brain 116(Part 5): 1159-1175.

Owen AM, Sahakian BJ, Semple J, Polkey CE, Robbins TW (1995). Visuo-spatial short-term recognition memory and learning after temporal lobe excisions, frontal lobe excisions or amygdalohippocampectomy in man. Neuropsychologia 33: 1-24.

Pantelis C, Barber FZ, Barnes TR, Nelson HE, Owen AM, Robbins TW (1999). Comparison of set-shifting ability in patients with chronic schizophrenia and frontal lobe damage. Schizophr Res 37: 251-270.

Pantelis C, Brewer W (1995). Neuropsychological and olfactory dysfunction in schizophrenia: relationship of frontal syndromes to syndromes of schizophrenia. Schizophr Res 17: 35-45.

Robbins TW, James M, Owen AM, Sahakian BJ, McInnes L, Rabbitt P (1994). Cambridge neuropsychological test automated battery (CANTAB): a factor analytic study of a large sample of normal elderly volunteers. Dementia 5: 266-281.

Rogers RD, Blackshaw AJ, Middleton HC, Matthews K, Hawtin K, Crowley C et al (1999). Tryptophan depletion impairs stimulusreward learning while methylphenidate disrupts attentional control in healthy young adults: implications for the monoaminergic basis of impulsive behaviour. Psychopharmacology (Berl) 146: 482-491.

Rubia K, Russell T, Bullmore ET, Soni W, Brammer MJ, Simmons A et al (2001). An fMRI study of reduced left prefrontal activation in schizophrenia during normal inhibitory function. Schizophr Res 52: 47-55. 
Scammell TE, Estabrooke IV, McCarthy MT, Chemelli RM, Yanagisawa M, Miller MS et al (2000). Hypothalamic arousal regions are activated during modafinil-induced wakefulness. J Neurosci 20: 8620-8628.

Sevy S, Davidson M (1995). The cost of cognitive impairment in schizophrenia. Schizophr Res 17: 1-3.

Sharma RP, Javaid JI, Pandey GN, Janicak PG, Davis JM (1991). Behavioral and biochemical effects of methylphenidate in schizophrenic and nonschizophrenic patients. Biol Psychiatry 30: 459-466.

Spaulding WD, Fleming SK, Reed D, Sullivan M, Storzbach D, Lam M (1999). Cognitive functioning in schizophrenia: implications for psychiatric rehabilitation. Schizophr Bull 25: 275-289.

Spohn HE, Strauss ME (1989). Relation of neuroleptic and anticholinergic medication to cognitive functions in schizophrenia. J Abnorm Psychol 98: 367-380.

Stuss DT, Benson DF, Kaplan EF, Weir WS, Naeser MA, Lieberman I et al (1983). The involvement of orbitofrontal cerebrum in cognitive tasks. Neuropsychologia 21: 235-248.

Szeszko PR, Bilder RM, Dunlop JA, Walder DJ, Lieberman JA (1999). Longitudinal assessment of methylphenidate effects on oral word production and symptoms in first-episode schizophrenia at acute and stabilized phases. Biol Psychiatry 45: 680-686.

Taylor FB, Russo J (2000). Efficacy of modafinil compared to dextroamphetamine for the treatment of attention deficit hyperactivity disorder in adults. J Child Adolesc Psychopharmacol 10: 311-320.

Taylor MA, Abrams R (1987). Cognitive impairment patterns in schizophrenia and affective disorder. J Neurol Neurosurg Psychiatry 50: 895-899.

Turner DC, Clark L, Dowson J, Robbins TW, Sahakian BJ (2004). Modafinil improves cognition and response inhibition in adult ADHD. Biol Psychiatry, (in press).
Turner DC, Robbins TW, Clark L, Aron AR, Dowson J, Sahakian BJ (2003a). Cognitive enhancing effects of modafinil in healthy volunteers. Psychopharmacology (Berl) 165: 260-269.

Turner DC, Robbins TW, Clark L, Aron AR, Dowson J, Sahakian BJ (2003b). Relative lack of cognitive effects of methylphenidate in elderly male volunteers. Psychopharmacology (Berl) 168: 455-464.

Wechsler D (1981). Wechsler Adult Intelligence Scale-Revised. The Psychological Corporation: New York.

Weinberger DR, Berman KF, Zec RF (1986). Physiologic dysfunction of dorsolateral prefrontal cortex in schizophrenia. I. Regional cerebral blood flow evidence. Arch Gen Psychiatry 43: 114-124.

Wisor JP, Nishino S, Sora I, Uhl GH, Mignot E, Edgar DM (2001). Dopaminergic role in stimulant-induced wakefulness. J Neurosci 21: 1787-1794.

Wong YN, King SP, Laughton WB, McCormick GC, Grebow PE (1998). Single-dose pharmacokinetics of modafinil and methylphenidate given alone or in combination in healthy male volunteers. J Clin Pharmacol 38: 276-282.

Wykes T, Reeder C, Corner J (2000). The prevalence and stability of an executive processing deficit, response inhibition, in people with chronic schizophrenia. Schizophr Res 46: 241-253.

Wykes T, Reeder C, Corner J, Williams C, Everitt B (1999). The effects of neurocognitive remediation on executive processing in patients with schizophrenia. Schizophr Bull 25: 291-307.

Wykes T, Reeder C, Williams C, Corner J, Rice C, Everitt B (2003). Are the effects of cognitive remediation therapy (CRT) durable? Results from an exploratory trial in schizophrenia. Schizophr Res 61: $163-174$

Yu BP, Maguire GA, Liffick TF (2002). Modafinil for treatment of the negative symptoms of schizophrenia and antipsychoticinduced sedation. Sleep 25: A503-A504. 